Stanisław Borkowski ${ }^{1}$, Agnieszka Noga ${ }^{2}$

\title{
WARIANTY PREZENTACJI WYNIKÓW ZAKRESU OCENY FUNKCJONOWANIA PROCESU PRODUKCJI WYROBÓW SPOŻYWCZYCH
}

\begin{abstract}
Streszczenie: Funkcjonowanie przedsiębiorstwa branży spożywczej zostało poddane analizie w oparciu o szósty obszar ankiety BOST. Interpretację wyników prowadzono na podstawie tablic, histogramów, wykresów radarowych, diagramów Pareto-Lorenza oraz szeregów ważności opisanych czynników.
\end{abstract}

Stowa kluczowe: doskonalenie procesu produkcji, ankieta BOST,

\section{Wprowadzenie}

Dzisiejsze przedsiębiorstwa produkcyjne powinny podejmować działania doskonalące, aby redukować koszty, spełniać coraz częściej bardzo rygorystyczne wymagania znajdujących się w normach i wytycznych organów nadzorczych, a przede wszystkim podnosić jakość produktów. Dlatego doskonalenie to termin, który najczęściej używany jest w zakresie zarządzania jakością. Doskonalone są przede wszystkim wyroby, usługi, a przy tym jednocześnie metody, procesy, ale także i personel. Doskonalenie zawiera działania z zakresu drobnego ulepszenia do znacznego doskonalenia całej organizacji. Najważniejsze jest jednak, aby takie postępowanie było ciągłym procesem.

Każdy proces produkcyjny musi podlegać stałej ocenie i procesom doskonalenia.

Obiektem badawczym jest piekarnia, która zatrudnia obecnie 35 pracowników. Do własnej produkcji piekarniczej piekarnia zalicza:

\footnotetext{
${ }^{1}$ Prof. n. techn. i n. ekon. Dr hab. Inż., Politechnika Częstochowska, Wydział Zarządzania, Instytut Inżynierii Produkcji, e-mail: bork@zim.pcz.pl

2 Mgr, Politechnika Częstochowska, Wydział Zarządzania, Instytut Ekonometrii i Informatyki, e-mail: agnieszkanoga@ poczta.onet.pl
} 
wyroby piekarskie, półcukiernicze, bułkę tartą. Produkowany asortyment piekarni można podzielić na następujące rodzaje pieczywa:

- pieczywo mieszane,

- pieczywo żytnie,

- pieczywo pszenne,

- pieczywo półcukiernicze,

- pieczywo cukiernicze,

- pieczywo pozostałe,

- pieczywo okolicznościowe.

Głównym jednak produktem produkowanym przez piekarnie jest chleb mieszany wypiekany z mąki żytniej i pszennej typu $500 \mathrm{w}$ różnych proporcjach. Do posypania chleba możliwe jest zastosowanie maku, natomiast do posypywania koszyczków/foremek używane są otręby.

\section{Struktura cech respondentów}

Opisując przedsiębiorstwo należy pamiętać, że ważnym czynnikiem jest człowiek. W badaniu BOST, które zostało przeprowadzone w piekarni, udział wzięło 30 respondentów w tym 28 pracowników wykonawczych i 2 osoby z kadry kierowniczej. Cechy osobiste respondentów stają się w tych badaniach zmiennymi objaśniającymi.

\subsection{Wykorzystanie wykresów radarowych do prezentacji struktury cech respondentów}

Rysunek 1 zawiera graficzną formę (wykresy radarowe) prezentacji struktury liczbowej respondentów. 

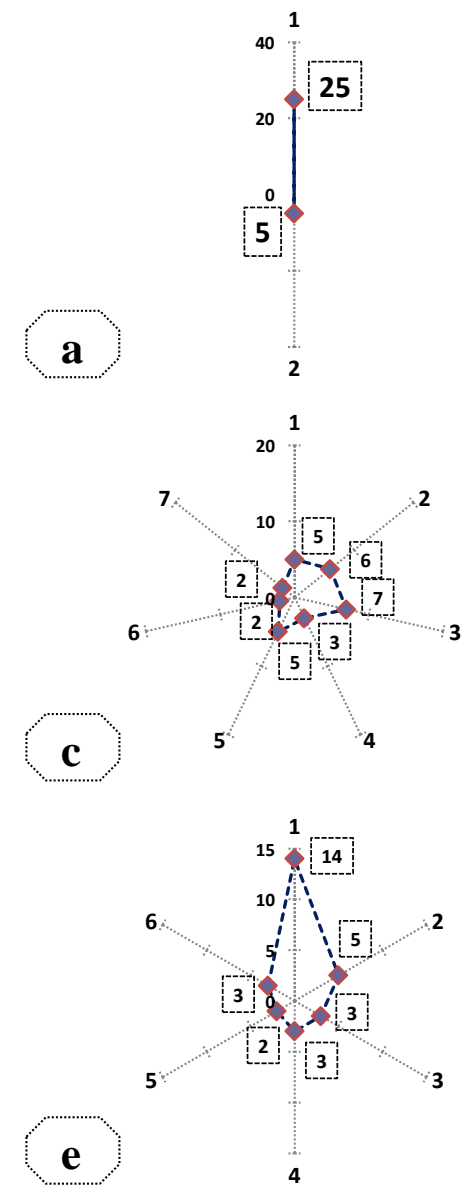

Rys. 1. Wykresy radarowe. Charakterystyka liczbowa respondentów z uwzględnieniem: a) plci, b) wyksztalcenia, c) wieku, d) stażu, e) mobilności, f) trybu przyjęcia do pracy. Dotyczy produkcji pieczywa.

Źródto: opracowanie własne

Statystycznie w badanym przedsiębiorstwie respondent to mężczyzna posiadający wykształcenie średnie $\mathrm{w}$ wieku 41 - 50 lat, pracujący 
zawodowo 21 - 25 lat, dla którego obecne miejsce pracy jest pierwszym miejscem zatrudnienia i został przyjęty w tak zwanym trybie normalnym.

\section{Struktura ocen $\mathrm{z}$ ankiety BOST}

Badania przeprowadzone za pomocą ankiety BOST (związana z zasadami zarządzania Toyoty) pozwoliły na analizę ocen ważności czynników opisujących rodzaj standaryzacji zapewniający ciągłą poprawę procesów $\mathrm{w}$ przedsiębiorstwie

Analizie został poddany zestaw czynników, który dotyczył odpowiedzi na następujące pytanie:

Jaki rodzaj standaryzacji jest najważniejszy w zapewnieniu ciągłej poprawy procesów w Państwa firmie?

Respondenci oceniali ważność wymienionych czynników w skali od 1 do 7 wpisując odpowiednią cyfrę w okienko obok symbolu każdego z siedmiu czynników:

- czas wykonywania jednego zadania $(\mathrm{CW})$,

- $\operatorname{proces}(\mathrm{PU})$,

- magazyny przystanowiskowe (MP),

- dokumenty (DO),

- $\quad$ szkolenia $(\mathrm{SN})$,

- przepływ informacji (PI),

- zatrudnienie (ZA) (BORKOWSKI S. 2013).

\subsection{Zestawienie ocen ważności czynników w tablicach}

Procentowe zestawienie ocen ważności czynników opisujących zasadę 6 zarządzania Toyoty przedstawiono w tablicy 1 .

Według badanych najważniejszym czynnikiem standaryzacji jest proces (PU). Na ten czynnik wskazało 50\% ankietowanych przyznając mu ocenę 7. Natomiast jako najmniej istotny czynnik respondenci uznali przystanowiskowe magazyny (MP). 
Tablica 1. Zasada 6. Procentowe zestawienie ocen ważności czynników obszaru E6. Dotyczy produkcji pieczywa

\begin{tabular}{|c|c|c|c|c|c|c|c|}
\hline \multirow{2}{*}{ Ocena } & \multicolumn{7}{|c|}{ Oznaczenie czynników } \\
\cline { 2 - 8 } & CW & PU & MP & DO & SN & PI & ZA \\
\hline 1 & 0,0 & 3,3 & 66,7 & 16,7 & 6,7 & 3,3 & 3,3 \\
\hline 2 & 0,0 & 0,0 & 16,7 & 43,3 & 10,0 & 16,7 & 13,3 \\
\hline 3 & 3,3 & 3,3 & 6,7 & 13,3 & 30,0 & 20,0 & 23,3 \\
\hline 4 & 10,0 & 6,7 & 0,0 & 10,0 & 33,3 & 30,0 & 10,0 \\
\hline 5 & 33,3 & 13,3 & 3,3 & 6,7 & 6,7 & 3,3 & 33,3 \\
\hline 6 & 26,7 & 23,3 & 6,7 & 6,7 & 10,0 & 13,3 & 13,3 \\
\hline 7 & 26,7 & 50,0 & 0,0 & 3,3 & 3,3 & 13,3 & 3,3 \\
\hline
\end{tabular}

Źródło: opracowanie własne

Ocenę 1 przyznało mu aż 66,7\% badanych. Czynnik czas wykonywania jednego zadania $(\mathrm{CW})$ uzyskał ocenę 6 i 7 na poziomie 26,7\%. 43,3\% badanych przyznało ocenę 2 dokumentom (DO). 33,3\% respondentów przyznało ocenę 4 szkoleniom (SN). Najwyższa ocena dla przepływu informacji uzyskała ocena 4 (30\%). 33,3\% respondentów przyznało ocenę 5 zatrudnieniu (ZA).

W tablicy 2 zaprezentowano miejsce analizowanego czynnika w szeregu ważności dla poszczególnych ocen dotyczących produkcji pieczywa.

Zauważamy, że dla oceny "1" szereg ważności przedstawia się następująco:

czynnik MP (magazynowanie przystanowiskowe) w tym szeregu zajmuje pierwsze miejsce, a ostatnie czynnik $\mathrm{CW}$ (czas wykonania jednego zadania). itd. 
Tablica 2. Zasada 6. Miejsce czynnika obszaru E6 w szeregu ważności dla poszczególnych ocen. Dotyczy produkcji pieczywa

\begin{tabular}{|c|c|c|c|c|c|c|c|}
\hline \multirow{2}{*}{ Ocena } & \multicolumn{7}{|c|}{ Miejsce czynników Szeregu ważności } \\
\cline { 2 - 8 } & $\mathbf{1}$ & $\mathbf{2}$ & $\mathbf{3}$ & $\mathbf{4}$ & $\mathbf{5}$ & $\mathbf{6}$ & $\mathbf{7}$ \\
\hline $\mathbf{1}$ & $M P$ & $D O$ & $S N$ & $P I$ & $P U$ & $Z A$ & $C W$ \\
\hline 2 & $D O$ & $M P$ & $P I$ & $Z A$ & $S N$ & $C W$ & $P U$ \\
\hline 3 & $S N$ & $Z A$ & $P I$ & $D O$ & $M P$ & $C W$ & $P U$ \\
\hline 4 & $S N$ & $P I$ & $C W$ & $D O$ & $Z A$ & $P U$ & $M P$ \\
\hline 5 & $C W$ & $Z A$ & $P U$ & $D O$ & $S N$ & $M P$ & $P I$ \\
\hline 6 & $C W$ & $P U$ & $P I$ & $Z A$ & $S N$ & $D O$ & $M P$ \\
\hline 7 & $P U$ & $C W$ & $P I$ & $D O$ & $S N$ & $Z A$ & $M P$ \\
\hline
\end{tabular}

Źródto: opracowanie własne

3.2. Wykorzystanie diagramów Pareto-Lorenza do budowy szeregów ważności czynników opisujących zasadę szóstą Toyoty

Dla dokładniejszej analizy ważności czynników opisujących zasadę 6 zarządzania Toyoty wyniki przedstawiono w postaci wykresów ParetoLorenza na rysunku 2.
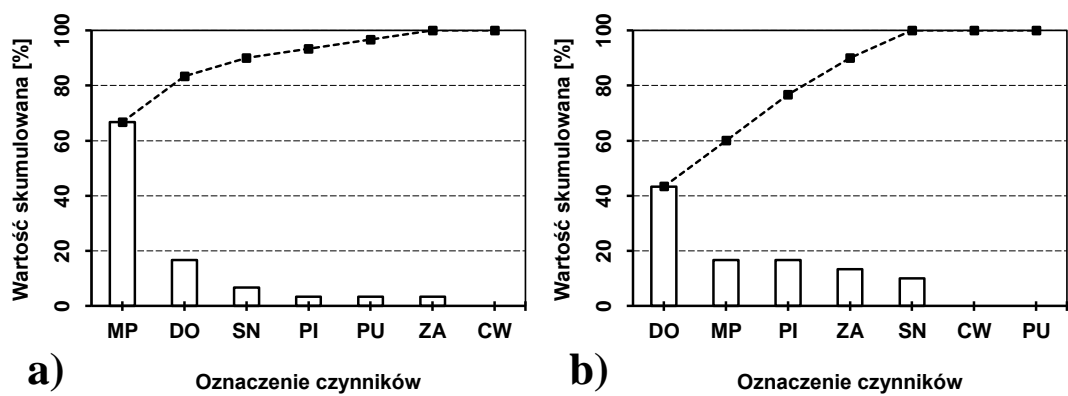

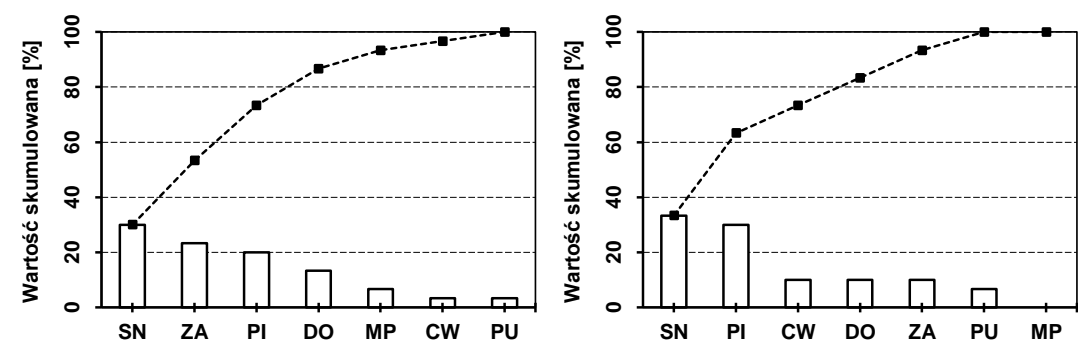

c)

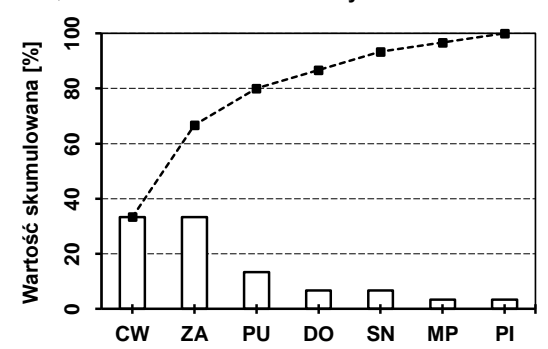

e)

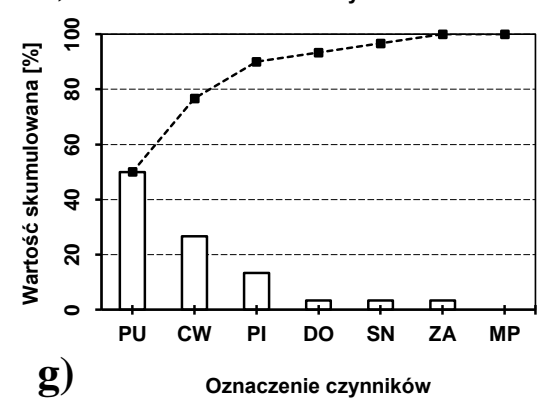

d)

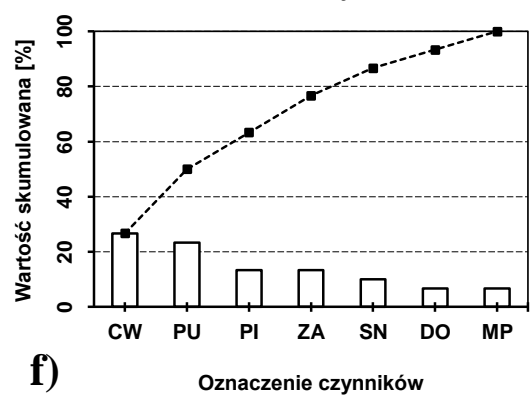

Rys. 2. Zasada 6. Diagramy ParetoLorenza ważności czynników obszaru E6 dla ocen: a) ,1", b) „2”, c) ,3”, d) ,4, e) ,5”,f), ,6”, g),7”.

Źródto: opracowanie własne

$\mathrm{Z}$ rysunku 2 wynika że, najważniejszym elementem wg badanych jest proces (PU), któremu przydzielili badani ocenę 7 oddając 50\% głosów (rysunek 2g). Natomiast największa liczba ankietowanych (66,7\%) oceniła magazyny przystanowiskowe (MP), jako najmniej znaczący czynnik w standaryzacji. 


\subsection{Budowa szeregów ważności podmiotowych czynników}

Przechodząc do prezentacji szeregów ważności czynników dla poszczególnych ocen należy przeanalizować tablice 1 i 2 oraz diagramy Pareto-Lorenza. Okazuje się, że to samo można przedstawić w postaci bardzo czytelnych wzorów:

Dla oceny 1

$$
\mathrm{MP}>\mathrm{DO}>\mathrm{SN}>(\mathrm{PI} \text { PU; } \mathrm{ZA})>\mathrm{CW}
$$

Dla oceny 2

$$
\mathrm{DO}>(\mathrm{MP} ; \mathrm{PI})>\mathrm{ZA}>\mathrm{SN}>(\mathrm{CW} ; \mathrm{PU})
$$

Dla oceny 3

$$
\mathrm{SN}>\mathrm{ZA}>\mathrm{PI}>\mathrm{DO}>\mathrm{MP}>(\mathrm{CW} ; \mathrm{PU})
$$

Dla oceny 4

$$
\mathrm{SN}>\mathrm{PI}>(\mathrm{CW} ; \mathrm{DO} ; \mathrm{ZA})>\mathrm{PU}>\mathrm{MP}
$$

Dla oceny 5

$$
(\mathrm{CW} ; \mathrm{ZA})>\mathrm{PU}>(\mathrm{DO} ; \mathrm{SN})>(\mathrm{MP} ; \mathrm{PI})
$$

Dla oceny 6

$$
\mathrm{CW}>\mathrm{PU}>(\mathrm{PI} ; \mathrm{ZA})>\mathrm{SN}>(\mathrm{DO} ; \mathrm{MP})
$$

Dla oceny 7

$$
\mathrm{PU}>\mathrm{CW}>\mathrm{PI}>(\mathrm{DO} ; \mathrm{SN} ; \mathrm{ZA})>\mathrm{MP}
$$

We wzorze (11.7) czynnik - proces (PU) przeważa nad czynnikiem czas wykonania jednego zadania $(\mathrm{CW})$ natomiast najmniejszy procent uzyskanych najwyższych ocen ma czynnik - magazyny przystanowiskowe (MP), który we wzorze (1) zajął pierwsze miejsce w strukturze ważności ocen.

W analizie omawianej zależności należy uwzględnić pewne wyróżnienie znajdujące się $\mathrm{w}$ przedstawionych wzorach. Dotyczy to pojawienia się nawiasów. W nawiasie wymieniono czynniki posiadające identyczną wartość procentową uzyskania danej oceny u respondentów. Liczba jednakowego poziomu jest różna dla poszczególnych ocen. Dla oceny "2" są dwie pary takich czynników, dla oceny "3" jedna para, dla 
"5" trzy pary, dla "6" dwie pary. Dla trzech ocen, a mianowicie dla oceny 1, 4 i 7 występują po trzy wartości jednakowe. (trzy czynniki są w nawiasie)

\section{Podsumowanie i wnioski}

Wyniki analiz i badań wykazały, iż w ocenie badanych (respondentów) najważniejsze w piekarni są procesy, a najmniej ważne magazyny przystanowiskowe. Rozpatrywana zasada 6 określiła ważność poszczególnych czynników również ze względu na średnie oceny co przedstawia rysunek 3 .

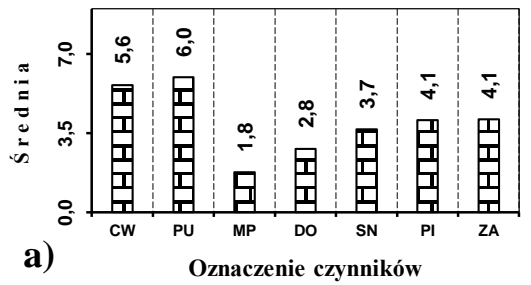

\section{Rys. 3. Średnie (liczbowe) oceny ważności czynników obszaru E6. Dotyczy produkcji pieczywa.}

Źródto: opracowanie własne

Najwyżej ocenionym czynnikiem jest czynnik oznaczony PU

(średnia wynosi 6,0) oraz CW (średnia wynosi 5,6). Czynnik oznaczony MP zdaniem respondentów nie jest ważny w analizowanym przedsiębiorstwie, posiada najniższą średnią $(1,8)$.

Podsumowując badanie średnich możemy zapisać szereg ważności ocen czynników ze względu na ich wartości średnie (wzór 8).

$$
\mathrm{PU}>\mathrm{CW}>(\mathrm{PI} ; \mathrm{ZA})>\mathrm{SN}>\mathrm{DO}>\mathrm{MP}
$$

Do analizy istotności zróżnicowania średnich zostało wykorzystanych siedem opisywanych czynników ankiety BOST, dotyczącej szóstej zasady zarządzania Toyoty. Analiza zróżnicowania średnich pomaga porównać wartości krytyczne do wartości testu dla każdego z poszczególnych czynników. 
Rysunek 4 dotyczy liczby istotnie zróżnicowanych ocen dla poziomu $\alpha=0,05 ; \alpha=0,1$ i $\alpha=0,2$.

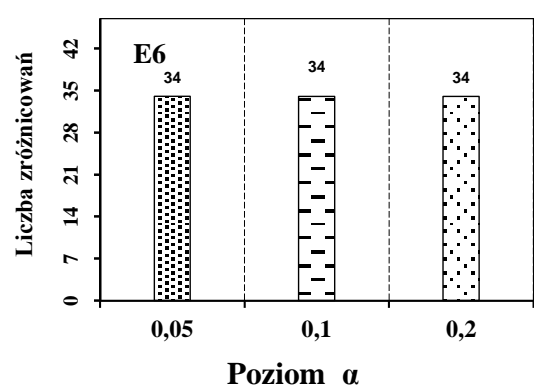

Rys. 4. Histogramy. Liczba istotnie zróżnicowanych średnich ocen ważności czynników obszaru E6 dla różnych a. Dane z powtórzeniami. Dotyczy produkcji pieczywa.

Źródto: opracowanie własne

Spośród wszystkich analizowanych czynników zasady 6 zróżnicowanie średnich jest istotne statystycznie na wszystkich poziomach $\alpha$ po 34 razy.

Analiza korelacyjna jest jedna z kolejnych analiz przeprowadzanych na podstawie badań BOST. Podkreśla ona znaczenie cech respondentów w kształtowaniu ocen ważności czynników. Przedstawia ją rysunek 5.

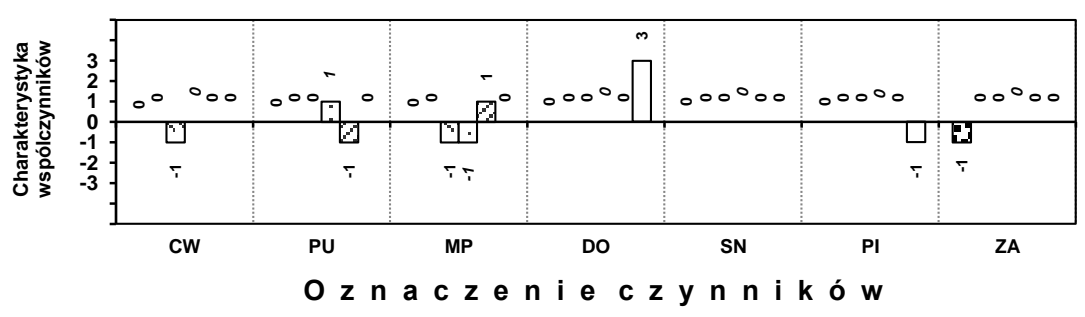

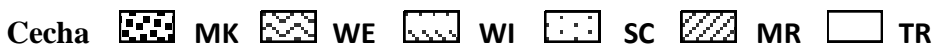
1; 2; 3 liczba statystycznie istotnych wspótczynników korelacji. (+) korelacja dodatnia, (-) korelacja ujemna

Rys. 5. Zasada 6. Zestawienie wyników analizy korelacyjnej dla określenia wpływu cech respondentów na ważność czynników obszaru E6. Dotyczy produkcji pieczywa.

Źródto: opracowanie własne 
Zauważamy, że czynnik - szkolenia (SN) jest niezależny od cech respondentów. Natomiast, aż cztery czynniki: czas wykonania jednego zadania (CW), dokumenty (DO), przepływ informacji (PI) i zatrudnienie (ZA) zależą tylko od jednej cechy respondenta.

I tak odpowiednio:

- czas wykonania jednego zadania (CW) zależy od wieku,

- dokumenty (DO) i przepływ informacji (PI) zależy od trybu przyjęcia,

- zatrudnienie (ZA) zależy od płci.

Na cztery przypadki, w trzech jest to korelacja ujemna i tylko na poziomie $\alpha=0,2$ natomiast dla czynnika - dokumenty (DO) zależność ta występuje już na poziomie $\alpha=0,05$ i jest to korelacja dodatnia (na rys. jest 3 przy DO). Wyniki ocen ważności czynnika - proces (PU) są skorelowane od dwóch cech respondentów (stażu pracy i mobilności) na poziomie $\alpha=0,2$, przy czym kierunki ich wpływu są przeciwstawne. Staż pracy wpływa dodatnio, mobilność ujemnie na wyniki. Wyniki ocen ważności czynnika - magazyny przystanowiskowe (MP) są najbardziej wrażliwe na cechy respondentów. Na sześć cech trzy z nich wywierają wpływ; dwie (wiek i staż pracy) wpływ ujemny, jedna (mobilność miejsce pracy) dodatni. Jest to korelacja na poziomie $\alpha=0,2$.

Nawiązując do wymogów związanych z nazwaniem danego rodzaju badań metodą z powodzeniem stwierdzamy, że zaproponowane działania w BOST-cie spełniają warunki metody badań i opracowania wyników. Dlatego też metoda BOST znajduje swoje teoretyczne i praktyczne potwierdzenie, ponieważ każdy wzór opisujący szeregi ważności zawiera różny układ czynników.

$\mathrm{Na}$ zakończenie należy stwierdzić, że prezentowany materiał udokumentował przydatność metody BOST (związanej z zasadami zarządzania Toyoty) do oceny funkcjonowania procesu produkcyjnego (w piekarni). 


\section{Literatura}

1. BORKOWSKI S. 2013. Przydatność metody BOST do oceny funkcjonowania przedsiębiorstwa. Wyd. SMJiP. Częstochowa.

2. Borkowski S., Sygut P., RosaK-SzYrockA J. 2012. Wptyw cech respondentów na ważność czynników opisujacych realizacje ustug pocztowych. PORTAL PUBLIKACJI NAUKOWYCH Ewydawnictwo, artykuł dostępny na stronie internetowej: http://www.e-wydawnictwo.eu/Document/DocumentPreview/3315.

3. Borkowski S., UlewiCz R. 2009. Systemy produkcyjne. Wyd. Instytut Organizacji i Zarządzania w Przemyśle ORGMASZ. Warszawa.

4. LiBUDZISZ Z., KowAL K., ŻAKOwSKA Z. 2008. Mikrobiologia techniczna. Mikroorganizmy w biotechnologii, ochronie środowiska i produkcji żywności. Wyd. PWN. Warszawa.

5. INGALDI M. 2014. Najważniejsze rodzaje standaryzacji wykorzystywane w hucie. Rozdziat 7. [w:] BORKOWSKI S., INGALDI M. (red). Toyotaryzm. Ujęcie standaryzacji w metodzie BOST. Oficyna Wydawnicza Stowarzyszenia Menedżerów Jakości i Produkcji. Częstochowa. 